ЕЖОВ Дмитрий Александрович - кандидат политических наук; доцент, доцент департамента политологии и массовых коммуникаций Финансового университета при Правительстве РФ (125993, Россия, г. Москва, Ленинградский пр-кт, 49; president@lenta.ru)

\title{
ЭКОЛОГИЧЕСКИЕ ПРОТЕСТЫ: РЕКОНСТРУКЦИЯ ПРОБЛЕМНОГО ПОЛЯ
}

\begin{abstract}
Аннотация. В статье обобщается проблематика, лежащая в основе экологических протестов как инструмента деструктивной деятельности радикальных экоактивистов. Отмечается, что проблемное поле экологических протестов подвержено перманентному расширению вследствие массовизации экологической повестки и ретрансляции социального запроса. Отдельное внимание автор уделяет проектированию потенциальных проблемных тем, которые могут представлять интерес для радикальных политических экологов в обозримом будущем.
\end{abstract}

Keywords: экологический протест, радикальный экоактивизм, экологические организации, политические экологи, деструктивная деятельность, мусорный кризис

$\mathrm{P}$ ост экоактивизма на фоне усиления внимания к проблемам окружающей среды и осознания важности стратегически значимых проектов в соответствующей области формирует предпосылки для систематизации проблем, привлекающих внимание политических экологов. Непосредственным предметом исследовательского внимания выступает активность экологических организаций и движений, преследующих цели дестабилизации социально-политической обстановки, манипуляции общественным мнением вследствие организуемых ими серий протестных акций и информационных кампаний, использования экологической тематики в политических интересах. В отдельных случаях эти цели пересекаются. Деятельность таких организаций и движений политизирована и имеет ярко выраженный деструктивный характер. Ниже произведена попытка реконструкции проблемного поля реализуемых экопротестных проектов, имеющего тенденцию к расширению вследствие имеющегося социального запроса.

Актуализация экологической проблематики подтверждается результатами ряда исследований. Согласно данным опроса ВЦИОМа, опубликованным на официальном сайте Центра 10 января 2019 г., $79 \%$ россиян используют энергосберегающие лампочки; $74 \%$ экономят в быту воду, электричество и газ; $40 \%$ оказываются от личного автотранспорта; $32 \%$ участвуют в мероприятиях по озеленению территорий и экологических субботниках; $27 \%$ сортируют бытовой мусор; 23\% сдают опасный мусор, подлежащий обязательной утилизации, в специализированные пункты приема; $16 \%$ используют бумажные или тканевые сумки вместо полиэтиленовых пакетов; 10\% покупают товары из биоразлагаемых материалов и вторичного сырья. Примечательно, что только 5\% опрошенных заявили о своем участии в экологических протестных акциях и $3 \%-$ о том, что направляют денежные средства в поддержку фондов природы, заповедников, экологических организаций. Полагаем, что степень экологической активности обозначенных суммарных $8 \%$ опрошенных можно классифицировать как гладиаторскую, но в то же время по своему характеру она не во всех случаях будет рассматриваться в качестве радикальной.

Непосредственная радикализация экоактивистской деятельности воплощается в институционализированной форме и практически отображена в работе экологических организаций и движений, имеющей ярко выраженный политический аспект. В качестве приоритетного направления деятельности радикально настроенных политических экологов следует определить противодей- 
ствие реализации крупных инфраструктурных проектов путем применения широкого комплекса политических и юридических технологий. В качестве примеров, в частности, можно привести организацию технологического воздействия на строительство российского участка газопровода «Северный поток-2» в Калининградской обл. (Гринпис России, Балтийский фонд природы), освоение Уральской горно-металлургической компанией (УГМК) месторождений медно-никелевой руды в Воронежской обл. (экологические движения «Стоп, никель!» и «В защиту Хопра»), строительство Томинского горно-обогатительного комбината в Челябинской обл. (движение «Стоп ГОК!»), открытие новых угольных разрезов в Кузбассе (движения «Экозащита» и «Команда-29»). Стоит обратить внимание на то, что вмешательство в ход процессов подобного рода является непосредственной угрозой государственным интересам.

Спектр проблем, к которым апеллируют экоактивисты для оправдания своей деструктивной деятельности в рамках реализуемых ими кампаний, достаточно широк. В зависимости от содержания риторики выкристаллизовывается объект проектируемого технологического воздействия. Так, проводя кампании против вырубки зеленых насаждений, политические экологи на языке действий обращаются к представителям деревообрабатывающей промышленности и власти, которая в их представлении распродает народное достояние. Внимание экоактивистов к плотности застройки может мотивироваться обозначением проблемы загрязнения в особо охраняемых территориях вследствие нарушения нормы зеленых насаждений в расчете на одного жителя. В этом случае объектом воздействия выступают застройщики и опять же представители власти. Загрязнение воздуха экоактивистами воспринимается в виде борьбы с промышленными предприятиями и их владельцами. При всем этом апелляция экоактивистов к тем или иным причинам не всегда обоснованна, а приводимая ими аргументация в защиту собственной позиции зачастую не выдерживает критики.

Однако имеющая тренд к интенсификации массовизация экологической повестки и объективно формирующиеся социальные запросы заметно расширили проблемное поле деятельности экоактивистов. Так, за последние несколько лет особое значение приобрела тема так называемых мусорных бунтов. В конце 2010-х гг. в Российской Федерации экологический кризис в сфере обращения с твердыми коммунальными отходами обрел системный характер. Не лишним будет отметить, что тема экологических протестов, вызванных проблемой утилизации мусора, нашла свое отражение в деятельности Совета при Президенте РФ по развитию гражданского общества и правам человека. В рекомендациях, принятых в июне 2019 г. по итогам специального заседания, посвященного предотвращению образования отходов, на фоне фиксации роста жалоб и социальных протестов, вызванных нарушением прав граждан на охрану здоровья, санитарно-эпидемиологическое благополучие и благоприятную окружающую среду при обращении с отходами, упомянуто о факте проведения масштабных «антимусорных» протестов в начале 2019 г. в 30 российских регионах, что свидетельствует о придании так называемой мусорной проблеме общефедерального характера и поиске механизма ее решения на институциональном уровне.

В целом, в динамике с 2017 по 2019 г. число «мусорных бунтов» возрастает, а их география имеет тенденцию к расширению. В качестве наиболее резонансных примеров следует привести массовые протесты жителей Московской обл. в 2018 г., достигшие своего пика после отравления 50 детей ядовитым газом с мусорного полигона «Ядрово» в Волоколамске и последовавших за этим событий, а также серию протестов в период 2018-2019 гг. против стро- 
ительства мусорного полигона в районе станции Шиес в Архангельской обл. Объединяет эти два примера не только то, что разработка строительства полигона в Архангельской обл. стала по своей сути рефлексией протестов в Московской обл., приведших к закрытию большинства полигонов на территории региона и повлекших за собой необходимость поиска альтернативных способов утилизации мусора в отдаленных регионах России, но и то, что в рамках обеих протестных кампаний отмечены факты применения технологий, используемых радикальными экоактивистами. Так, общеизвестно, что в мае 2018 г. жители окрестных деревень перекрыли въезд на территорию закрытого участка карьера Сычевского ГОКа на территории Рузского района Московской обл., где, по мнению местных активистов, планировалось обустройство мусорного полигона взамен находящейся в 25 километрах действовавшей свалки в Ядрово, против которой выступали жители Волоколамска. В апреле 2019 г. были повреждены два моста на участке технологической дороги «Мадмас - Шыладор», использовавшиеся для проезда техники на стройку полигона на станции Шиес. Подобные случаи можно перечислять достаточно долго, но очевидным представляется предпочтение экоактивистами деструктивных способов реализации своей деятельности.

Если апеллировать к проспективной методике, то можно спрогнозировать потенциальные проблемные темы, которые могут привлечь внимание политических экологов в обозримом будущем и сформировать поводы для протестной активности. Базой для продуцирования подобных суждений, в частности, может служить анализ контента информационных вбросов, осуществляемых в рамках локальных кампаний в сети Интернет. Характерным примером может служить тематическое наполнение сервиса «Яндекс Район», предусматривающего свободное общение между жителями. Так, судя по обсуждаемым темам, пользователи сервиса принимают активное участие в обсуждении экологических проблем. Если обратиться к проблематике Московского региона, экопротестная активность может быть сосредоточена вокруг вопросов строительства участка юго-восточной хорды рядом с радиоактивной зоной на территории Московского завода полиметаллов; реализуемой политики по строительству транспортно-пересадочных узлов; естественной бактеризации почв отходами жизнедеятельности собак вследствие недостаточной инфраструктурной оснащенности процесса их утилизации. Заметим, что первые две проблемы нашли свое отражение в предвыборной риторике придерживающихся оппозиционных настроений кандидатов в депутаты Московской городской думы в 2019 г.; третья имеет системный характер и на данный момент находится в зоне внимания волонтерских движений. Полагаем, что обозначенные направления значительно расширят проблемное поле экологических протестов.

В заключение необходимо отметить, что проблемное поле экологических протестов имеет тенденцию к перманентному расширению. Внимание радикальных политических экологов могут привлекать проблемы, придание общественной значимости которым потенциально влечет за собой трансформацию в активность протестного характера.

Статья подготовлена по результатам исследований, выполненныхза счет бюджетных средств по государственному заданию Финансовому университету (2019). 
EZHOV Dmitriy Aleksandrovich, Cand.Sci. (Pol.Sci.), Associate Professor; Associate Professor of the Department of Political Science and Mass Communications, Financial University under the Government of the Russian Federation (49 Leningradsky Ave, Moscow, Russia, 125993; president@lenta.ru)

\title{
ENVIRONMENTAL PROTESTS: RECONSTRUCTION OF THE PROBLEM FIELD
}

Abstract. The article summarizes the issues that underlie environmental protests as a tool for the destructive activities of radical eco-activists. The author notes that the problem field of environmental protests is subjected to permanent expansion due to the massive environmental agenda and relaying of the social request. Special attention is paid to the design of potential problematic topics that may be of interest to radical political ecologists in the near future.

Keywords: environmental protest, radical eco-activism, environmental organizations, political ecologists, destructive activities, garbage crisis

БОЛЬШУНОВ Андрей Яковлевич - кандидат психологических наук, доцент; ведущий научный сотрудник Международного центра социальной экспертизы и развития Финансового университета при Правительстве РФ (125993, Россия, г. Москва, Ленинградский пp-кm, 49; andrey.bolshunov.1955@gmail.com)

ТЮРИКОВ Александр Георгиевич - доктор социологических наук, профессор, руководитель департамента социологии, истории и философии Финансового университета при Правительстве РФ (125993, Россия, г. Москва, Ленинградский пр-кm, 49; t-ag2013@yandex.ru)

БОЛЬШУНОВА София Андреевна - научный сотрудник Международного центра социальной экспертизы и развития Финансового университета при Правительстве РФ (125993, Россия, г. Москва, Ленинградский np-кm, 49; sophia.bolshunova@gmail.com)

\section{ТЕНДЕНЦИОЗНОСТЬ}

\section{В МЕЖНАЦИОНАЛЬНЫХ КОММУНИКАЦИЯХ: МЕХАНИЗМЫ ФОРМИРОВАНИЯ И ЭКСПАНСИИ, ПОДХОДЫ К КОРРЕКЦИИ}

\begin{abstract}
Аннотация. В статье рассматриваются механизмы формирования и экспансии тенденциозности в межнациональных коммуникациях, а также подходы к исследованию и коррекции этих механизмов. Авторы высказывают, обосновывают и обсуждают предположение, что ключевую роль в формировании и экспансии тенденциозности играет описанный А.Ж. Греймасом в актантной семантике механизм radotage (рус. - «вздор»). Этот механизм соотносится с явлениями диспозициональной атрибуции и «фундаментальной ошибки атрибуции", отождествляемой Л. Россом с диспозиционистской тенденциозностью, и, в отличие от атрибуции и диспозиционистской тенденциозности, является не социально-психологическим, а семантико-синтаксическим; соответственно, экспансия тенденциозности понимается как захват текстом (дискурсом) сознания. Интерпретативный феноменологический и нарративный анализ позволяют вскрыть работу этого механизма и осуществить коррекцию его функционирования.

Ключевые слова: межнациональные отношения и коммуникации, актантная (структурная) семантика, radotage, диспозиционистская тенденциозность, интерпретативный феноменологический анализ, нарративный анализ
\end{abstract}

$\mathrm{M}$ ежнациональные отношения легко приобретают конфронтационный характер (discourse of contradiction), и конфронтационные дискурсы в МНК характеризуются высокой устойчивостью и готовностью к манифестациям, 